\title{
Optimal Offering Strategies for Wind Power in Energy and Primary Reserve Markets
}

\author{
Soares, Tiago; Pinson, Pierre; Jensen, Tue Vissing; Morais, Hugo
}

Published in:

IEEE Transactions on Sustainable Energy

Link to article, DOI:

10.1109/TSTE.2016.2516767

Publication date:

2016

Document Version

Peer reviewed version

Link back to DTU Orbit

Citation (APA):

Soares, T., Pinson, P., Jensen, T. V., \& Morais, H. (2016). Optimal Offering Strategies for Wind Power in Energy and Primary Reserve Markets. IEEE Transactions on Sustainable Energy, 7(3), 1036-1045.

https://doi.org/10.1109/TSTE.2016.2516767

\section{General rights}

Copyright and moral rights for the publications made accessible in the public portal are retained by the authors and/or other copyright owners and it is a condition of accessing publications that users recognise and abide by the legal requirements associated with these rights.

- Users may download and print one copy of any publication from the public portal for the purpose of private study or research.

- You may not further distribute the material or use it for any profit-making activity or commercial gain

- You may freely distribute the URL identifying the publication in the public portal 


\title{
Optimal Offering Strategies for Wind Power in Energy and Primary Reserve Markets
}

\author{
Tiago Soares, Pierre Pinson, Senior Member, IEEE, Tue V. Jensen, and Hugo Morais, Member, IEEE
}

\begin{abstract}
Wind power generation is to play an important role in supplying electric power demand, and will certainly impact the design of future energy and reserve markets. Operators of wind power plants will consequently develop adequate offering strategies, accounting for the market rules and the operational capabilities of the turbines, e.g., to participate in primary reserve markets. We consider two different offering strategies for joint participation of wind power in energy and primary reserve markets, based on the idea of proportional and constant splitting of potentially available power generation from the turbines. These offering strategies aim at maximizing expected revenues from both market floors using probabilistic forecasts for wind power generation, complemented with estimated regulation costs and penalties for failing to provide primary reserve. A set of numerical examples, as well as a case-study based on real-world data, allows illustrating and discussing the properties of these offering strategies. An important conclusion is that, even though technically possible, it may not always make sense for wind power to aim at providing system services in a market environment.
\end{abstract}

Index Terms-Ancillary services, decision-making under uncertainty, electricity markets, offering strategies, wind power.

\section{NOMENCLATURE}

The main notation used throughout the paper is stated next for quick reference. Other symbols are defined as required.

A. Variables

$\alpha \quad$ Proportional strategy split for energy and reserve

$\lambda \quad$ Prices and costs in the electricity market

$E \quad$ Energy

$P \quad$ Power (reserve)

$Q \quad$ Total amount bid into day-ahead stage [MW]

$R \quad$ Total revenue

$T$ Regulation energy market revenue

$W \quad$ Potential penalty for primary reserve market

\section{B. Indices}

$+\quad$ Positive imbalance (downward regulation)

- Negative imbalance (upward regulation)

* Available energy/power at real-time stage

bpt Penalty cost for reserve imbalance [€/MW]

Manuscript received July 28, 2015; revised November 07, 2015 and December 17, 2015; accepted January 01, 2016. This work was supported by the Danish Council for Strategic Research (DSF) through the project "5 s Future Electricity Markets.” Paper no. TSTE-00621-2015.

Tiago Soares, Pierre Pinson, and Tue V. Jensen are with the Department of Electrical Engineering, Technical University of Denmark, Kgs. Lyngby 2800, Denmark (e-mail: tiasoar@elektro.dtu.dk).

Hugo Morais is with Département MIRE, EDF Lab Clamart, Clamart, France.

Color versions of one or more of the figures in this paper are available online at http://ieeexplore.ieee.org.

Digital Object Identifier 10.1109/TSTE.2016.2516767 c Contracted energy/power at day-ahead stage

cap Reserve price at day-ahead stage [€/MW]

obs Total eventually observed power [MWh]

pt Penalty for reserve imbalance [€/MW]

$r \quad$ Fixed reserve [MW]

sp Spot market

\section{INTRODUCTION}

$\mathbf{T}$ HE continuous deployment of wind power generation capacities in several countries, and especially in countries like Denmark, has an increasing impact on power system operation and electricity markets. For instance according to Energinet.dk (the Danish Transmission System Operator - TSO), December 2013 was an exceptional month where, on average, $54.8 \%$ of the electrical energy consumption was supplied by wind power [1]. According the same report, on December $1^{\text {st }}$, an extreme scenario with wind generation equal to $136 \%$ of the Danish power consumption was observed.

In the future, situations with very high wind (and most certainly also solar) generation will be more and more common, resulting in new challenges in power system operation [2]. The variability and limited predictability of wind power generation force the system operator to procure additional reserves to ensure adequate reliability of the electric power system [3]. However, according to [4] among others, wind power plants are able to provide reserves themselves, thereby reducing the additional procurement of reserves from other traditional resources. Thus, new mechanisms for reserve procurement, as well as for the participation of wind generation in providing reserves should be developed and implemented [5], [6]. Currently, wind turbine technology and wind farm control allow providing distinct ancillary services such as frequency and voltage control. Thus wind farms are able $(i)$ to provide and control active power injection in a few seconds, (ii) to respond to reactive power demands in less than 1 second, (iii) to support and maintain voltage levels, and (iv) to provide kinetic energy (virtual inertia) [4], [7]-[9].

Traditionally, primary reserve markets are designed to assist in dampening deviations from nominal frequency. Generators supply the service based on their inertia characteristics. Depending on the country rules, this service can either be supplied and priced through market mechanisms [4] or made mandatory without payment. With high penetration of variable generation, the service design tends to change, since reserve requirements may dynamically vary on an hourly or even minute basis [10], while the system may have lower inertia. Wind power plants and other emerging generating technologies 
may then be asked to contribute to this new service design [11], [12].

For optimal integration of wind power in energy and primary reserve markets, new business models and remuneration mechanisms should be thought of. The literature on optimal offering strategies for wind power producers in the day-ahead market while accounting for potential balancing costs has been flourishing over the last few years. This includes a number of studies (assuming that wind power producer act as a price-taker) on expected utility maximization strategies [13], [14], additional consideration on risk-aversion and temporal dependencies [15], extension to LMP markets [16] and multi-period setting to adjust contracted offerings [17], appraisal of uncertainties on both wind and market quantities [18], bidding under one-price and two-price system [19], generalized opportunity cost bidding [20], as well as minimizing imbalance costs accounting for wind power predictions and imbalance prices [21], among others. Although it is not the goal of the present paper to work on optimal strategies assuming that the wind power producer acts as a price-maker, readers are encouraged to consult these recent works [22]-[27] for detailed information.

In contrast, little attention has been paid to the joint offering under uncertainty of wind power generation in both energy and reserve markets [12], [28]. Liang et al. [12] proposes an analytical approach (based on the so called multi-newsvendor problem with budget constraint) for wind power participating in energy and reserve, assuming that offers for energy and reserve can be freely determined (i.e., independently of any control paradigm), since only subject to this budget constraint. Such joint offering strategies are expected to bring additional revenue streams to wind power plant operators. However, wind power plants face the challenge to guarantee that power scheduled as primary reserve is available at any time without failure. The reserve market is designed to ensure the operation of electric power systems with appropriate levels of stability, safety, quality, reliability and competitiveness. In this way, intermittent energy resources, such as wind power, have difficulties to ensure and fulfil power scheduled as primary reserve. Thus, a future reserve market must be designed to account for the possibility of wind failing to provide reserve, e.g. through penalties, if wind (or demand-response) is to participate in these markets.

This paper proposes an analytical approach for wind power participating in both energy and primary reserve markets taking into account the market penalties. The aim is to maximize the expected revenue from optimal offering on both energy and primary reserve markets. Our approach takes a different starting point is compared to previous work in the literature, e.g. [12], as instead of considering a budget constraint for the joint offering of energy and reserves, we first start from the various control paradigms described in the literature for wind to offer system services in practice. A major contribution of this work is the implementation, evaluation and comparison of two different offering strategies, namely the proportional and the constant wind strategies proposed in [29], [30], for the splitting of potentially available wind power considering the same wind distribution probability for the two services. In practice, they are easy to implement since uses simple controllers due to the locking of energy and reserve quantities [30], while strategies that utilize all operational degrees of freedom would require advanced controllers that are unlikely to admit analytical treatment, and may be highly susceptible of misestimate due to forecast errors. An advantage of our approach is then to show how offering behavior and market revenues can be highly affected by the control paradigm originally adopted. Both strategies are introduced with the motivation of allowing the split of the available wind power for energy and reserve. Furthermore, an economical evaluation of both strategies illustrating their advantages and inconveniences is undertaken. Optimal offers are determined under uncertainty based on probabilistic forecasts of potential power generation for the market time unit considered. Additional input variables include expected market prices (for energy and reserve) as well as expected penalties on balancing and reserve mechanisms. The methodology is applied and demonstrated on numerical examples. Wind power plants increase their profit by using these strategies for optimally offering in energy and reserve markets, thereby reducing the deviation penalties from the balancing market. Additionally, these strategies seek to motivate wind power penetration on power system, thereby, increasing the competition in both markets, as well as ensuring a cheap resource in the system operator standpoint. Besides that, future wind power plants will be able to provide fast reserve services that will be crucial in the operation of future power systems with high penetration of renewable resources [12]. Thus, system operators have interest in wind power participating in both energy and reserve markets.

The paper is structured as follows. Section II describes electricity markets characteristics with a perspective on future energy and reserve market trends. Section III presents the detailed formulation of joint offering strategies (for proportional and constant strategies) in energy and primary reserve markets. Section IV describes our empirical investigation based on a set of numerical examples. Section V assembles the most important conclusions.

\section{Wind POWER IN ELECTRICITY MARKETS}

\section{A. Current Day-Ahead and Balancing Market}

The increasing penetration of wind power generation in electric power systems has been changing wholesale market characteristics. In Denmark, wind power producers trade in the wholesale market and are remunerated through a combination of market price and premium [28]. This remuneration mechanism allows wind power owners to submit bids into the day-ahead market with zero or negative prices [29].

The balancing market is used to compensate for energy deviations in real time from the day-ahead and intra-day schedules. In a European context these are run by the local TSO [30]. For the example of Denmark, this market is cleared just before the operating hour and is divided into a regulating power market (where the system operator purchases the required regulating power to balance the system) and a balancing power market (where correction of the system and market participant imbalances is performed) [31]. For the case of wind power, the balancing market is the final mechanism permitting to mitigate forecast errors, and it can be highly penalizing. 


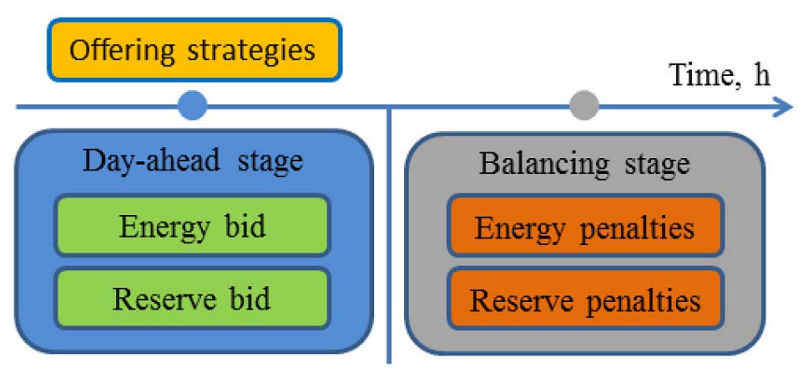

Fig. 1. Schematic representation of the market structure for the wind offering strategies.

\section{B. Joint Offering in Energy and Primary Reserve Markets}

Currently and even more in the future, wind power plants will be able to provide some type of ancillary services, such as frequency and voltage control [4]. Wind power plants are willing to participate in energy and primary reserve market only in the case where wind power producers may receive increased benefits from joint market participation, instead of participating in the energy market only. With that objective in mind, we will examine an analytical model for obtaining the optimal quantile bid of wind power participating in multiple markets with different expected prices and penalties for deviation from schedule.

The energy and reserve markets have different characteristics. On the one hand, wind energy bids submitted in the day-ahead market should account for potential imbalance situations and their asymmetric penalties. On the other hand, bids submitted in the primary reserve market are to accommodate the possibility to fail in providing the service, certainly associated with a much higher penalty. Fig. 1 presents the structure of the market for the offering strategies determination.

The bids submitted at the day-ahead market consider the expected costs in the balancing stage. In the formulation outlined here, the effect which the day-ahead bid has on the penalties of the balancing market, known as the time coupling effect, is not captured. We assume that any differences arising from this effect cancel out over time.

The formulation considers the important assumption of the split between energy and primary reserve remain the same in both day-ahead $\left(\alpha^{\mathrm{c}}\right)$ and balancing stages $\left(\alpha^{*}\right)$. This allows us to develop an analytical formulation to solve the problem. Future work may involve stochastic programming [32] allowing different energy and reserve share between day-ahead and balancing stages, thereby, reducing the time coupling effect.

\section{Methodology}

\section{A. General Formulation of Market Revenues}

The objective function to be optimized directly relates to the maximization of the combined revenue from day-ahead and reserve markets considering the penalties from the balancing market. Time indices are not used, since all variables and parameters are for the same market time unit. This combined revenue $R$ in real-time for a given wind power producer is expressed as

$$
R=\lambda^{s p} E^{*}+\lambda^{c a p} P^{*}-T^{*}-W^{*}
$$

where $\lambda^{s p}$ is the spot price, $E^{*}$ is the amount of delivered energy, $\lambda^{c a p}$ is the capacity price for primary reserve allocation, $P^{*}$ is the deployed level of primary reserve in real-time, $T^{*}$ is the regulation costs from the regulation market and $W^{*}$ is the penalty cost for wind power plant failing to provide the scheduled primary reserve.

In addition, we assume that the wind power producer acts as a price-taker. This means that the production of the wind power producer is independent of market prices and penalties. Because of this independence, and the fact that all prices enter linearly in the expressions below, all calculations depend only on the expected mean prices, rather than their full distribution. This reduction follows from certainty equivalent theory [36], and removes the need for a full stochastic description of prices using, e.g., scenarios [18]. In the following, we will refer to the sum of $\lambda^{s p} E^{*}$ and $\lambda^{c a p} P^{*}$ as the expected inflow. In parallel, the sum of $T^{*}$ and $W^{*}$ is referred to as expected costs. Subtracting the expected costs from the expected inflow yields the expected revenue of the wind power producer. In (1), the regulation costs are defined as

$$
T^{*}= \begin{cases}\lambda^{*,+}\left(E^{*}-E^{c}\right), & E^{*}-E^{c} \geq 0 \\ -\lambda^{*,-}\left(E^{*}-E^{c}\right), & E^{*}-E^{c}<0\end{cases}
$$

where $\left(E^{*}-E^{c}\right)$ is the energy imbalance between the energy delivered $E^{*}$ and the energy contracted (offered) $E^{c}$. The variables $\lambda^{*,+}$ and $\lambda^{*,--}$ are the regulation unit costs for positive and negative deviations, i.e.,

$$
\begin{aligned}
& \lambda^{*,+}=\lambda^{s p}-\lambda^{c,+} \\
& \lambda^{*,-}=\lambda^{c,-}-\lambda^{s p}
\end{aligned}
$$

where $\lambda^{c,+}$ is the unit down-regulation price for being long, while $\lambda^{c,--}$ is the up-regulation price for being short.

We place ourselves here in under two-price settlement rule, as in the NordPool [13]. In cases where the system imbalance is negative (energy surplus - need for downward regulation), it holds that

$$
\begin{aligned}
& \lambda^{c,+} \leq \lambda^{s p} \\
& \lambda^{c,-}=\lambda^{s p}
\end{aligned}
$$

In contrast, when system imbalance is positive (energy deficit - need of upward regulation), one has

$$
\begin{aligned}
& \lambda^{c,+}=\lambda^{s p} \\
& \lambda^{c,-} \geq \lambda^{s p}
\end{aligned}
$$

While finally during hours of perfect balance both $\lambda^{c,+}$ and $\lambda^{c,--}$ are equal to the spot price $\lambda^{s p}$. In parallel, the penalty costs for reserve imbalance can be written as

$$
W^{*}= \begin{cases}\lambda^{b p t,+}\left(P^{*}-P^{c}\right), & P^{*}-P^{c} \geq 0 \\ -\lambda^{b p t,-}\left(P^{*}-P^{c}\right), & P^{*}-P^{c}<0\end{cases}
$$




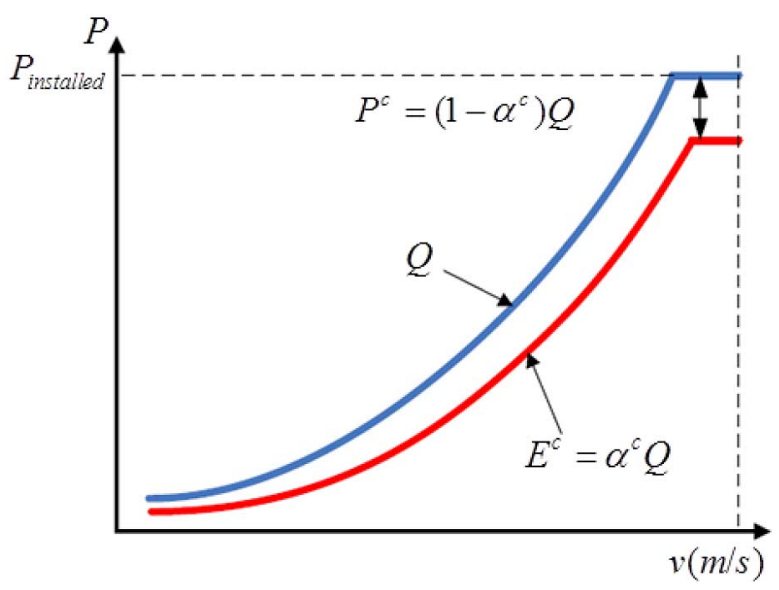

Fig. 2. Proportional wind offering strategy (reproduced with authorization from [29], [30]).

where $\left(P^{*}-P^{c}\right)$ is the primary reserve power imbalance between the realized level of reserve $P^{*}$ and the reserve contracted (offered) $P^{c} \cdot \lambda^{b p t,+}$ is a unit penalty when wind producer generator more power than the contracted (surplus), and $\lambda^{b p t,--}$ is the unit penalty cost when wind power producer generate less than contracted. These are given by

$$
\begin{aligned}
& \lambda^{b p t,+}=\lambda^{c a p}-\lambda^{p t,+} \\
& \lambda^{b p t,-}=\lambda^{p t,-}-\lambda^{c a p}
\end{aligned}
$$

hence $\lambda^{p t,+}=0$ since (extra) positive reserve is not detrimental to the system's reliability. $\lambda^{p t,--}$ is the penalty for negative reserve imbalance, weighted by the probability that reserve is needed.

In principle, a wind power producer can bid any $E^{c}, P^{c} \geq 0$ into the day-ahead market, and choose to deliver any amount $E^{*}, P^{*} \geq 0$ in real time, bounded by $E^{*}+P^{*} \leq E^{o b s}$, the observed energy. To make the problem analytically tractable, we proceed by constraining the choice of $E^{*}$ and $P^{*}$ based on $E^{c}$ and $P^{c}$. This restriction is performed through the use of two known strategies, which have been previously shown to be operationally feasible [26], [27]. The following subsections define these strategies, while the analytical optimal bids are finally given.

\section{B. Proportional Wind Offering Strategy}

The proportional wind offering strategy (illustrated in Fig. 2) consists in a proportional curtailment of available power generation to yield an energy offer $E^{c}$ and a primary reserve offer $P^{c}$ [29], where

$$
\begin{aligned}
& E^{c}=\alpha^{c} Q \\
& P^{c}=\left(1-\alpha^{c}\right) Q
\end{aligned}
$$

In the above, $Q$ denotes the total power bid in MW for that market time unit and $\alpha^{c}$ is the strategy parameter controlling the proportional split between energy and primary reserve bids. This last parameter naturally varies between 0 (for full reserve allocation) and 1 (for full energy allocation).

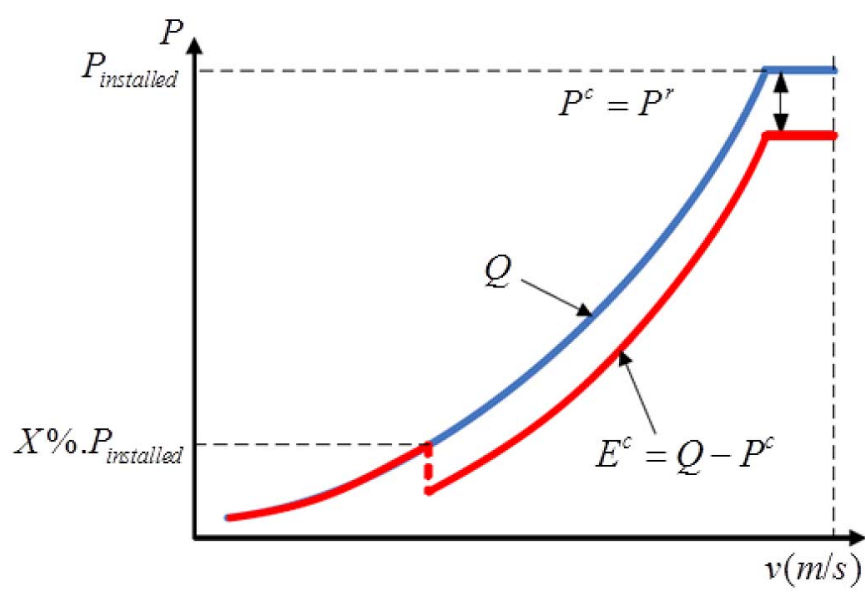

Fig. 3. Constant wind offering strategy (reproduced with authorization from [29], [30]).

On the other hand, the eventually observed wind power production $E^{o b s}$ is similarly composed of an energy portion $E^{*}$ and $P^{*}$ the amount of primary reserve actually available,

$$
\begin{aligned}
& E^{*}=\alpha^{*} E^{o b s} \\
& P^{*}=\left(1-\alpha^{*}\right) E^{o b s}
\end{aligned}
$$

where $\alpha^{*}$ is the strategy parameter used when reaching realtime operation. It is assumed that strategy parameter in dayahead and real-time are the same $\alpha^{*}=\alpha^{c}$.

\section{Constant Wind Offering Strategy}

The constant wind offering strategy (Fig. 3) is based on a constant curtailment of energy when the expected energy produced is over a certain expected level of wind power [26], where

$$
\begin{aligned}
& E^{c}=Q-P^{c} \\
& P^{c}=P^{R}
\end{aligned}
$$

$P^{R}$ is the amount of fixed reserve to be submitted in the primary reserve market, and $X \%$ is the percentage of installed wind power.

Similar to the proportional strategy, the observed wind production $E^{o b s}$ is related to $E^{*}$. The reserve amount is assumed to be constant and fixed in day-ahead decision. That is, priority delivery of the reserve is assumed. The delivered amount of energy and primary reserve may be written as

$$
\begin{aligned}
& E^{*}=E^{o b s}-P^{*} \\
& P^{*}=P^{r}
\end{aligned}
$$

\section{Analytical Derivation of Optimal Bids}

\section{A. Proportional Strategy Optimization Problem}

Assuming that the wind power plant acts as a price-taker, the maximization of its expected revenues is equivalent to the minimization of the expectation of regulation and penalty costs. 
Optimal offers are then the solution of

$$
\left(\tilde{Q}, \tilde{\alpha}^{c}\right)=\underset{Q, \alpha^{c}}{\operatorname{Erg}} \min \left\{T^{*}+W^{*}-\lambda^{s p} E^{*}-\lambda^{c a p} P^{*}\right\}
$$

The loss function in the above comprises an extended version of that used in [13], where here, the available wind power is split into two different market products. The share of the available expected power $\alpha^{c}$ and observed power $\alpha^{*}$ for energy and reserve participation is the same $\left(\alpha^{*}=\alpha^{\mathrm{c}}\right)$. Consequently, the total expected costs $O$ are given by

$$
\begin{aligned}
O\left(Q, \alpha^{c}\right)= & \int_{0}^{Q}\left[\begin{array}{c}
\lambda^{*,-} \alpha^{c}(Q-x)+ \\
\lambda^{b p t,-}\left(1-\alpha^{c}\right)(Q-x)- \\
\lambda^{s p} \alpha^{c} x-\lambda^{c a p}\left(1-\alpha^{c}\right) x
\end{array}\right] f(x) d x \\
& +\int_{Q}^{1}\left[\begin{array}{c}
\lambda^{*,+} \alpha^{c}(x-Q)- \\
\lambda^{s p} \alpha^{c} x-\lambda^{c a p}\left(1-\alpha^{c}\right) Q
\end{array}\right] f(x) d x
\end{aligned}
$$

where $f(x)$ is the forecast probability density function of the wind power plant production. To analytically solve the problem the Leibniz rule is used. The Leibniz rule, for an arbitrary function $f$, parameters $\theta$, and integration bounds $a$ and $b$, tells that

$$
\begin{aligned}
\frac{\partial}{\partial \theta}\left(\int_{a(\theta)}^{b(\theta)} f(x, \theta)\right)= & \int_{0}^{1} \partial_{\theta} f(x, \theta) d x+f(b(\theta), \theta) \cdot b^{\prime}(\theta) \\
& -f(a(\theta), \theta) \cdot a^{\prime}(\theta)
\end{aligned}
$$

Thus, the derivative of (13) with respect to $Q$ is given by

$$
\begin{aligned}
\frac{\partial O}{\partial Q}\left(Q, \alpha^{c}\right)= & \int_{0}^{Q}\left[\lambda^{*,-} \alpha^{c}+\lambda^{b p t,-}\left(1-\alpha^{c}\right)\right] f(x) d x \\
& -\left[\lambda^{s p} \alpha^{c} Q+\lambda^{c a p}\left(1-\alpha^{c}\right) Q\right] f(Q) \\
& +\int_{Q}^{1}\left[-\lambda^{*,+} \alpha^{c}-\lambda^{c a p}\left(1-\alpha^{c}\right)\right] f(x) d x \\
& +\left[\lambda^{s p} \alpha^{c} Q+\lambda^{c a p}\left(1-\alpha^{c}\right) Q\right] f(Q)
\end{aligned}
$$

The optimal bid is obtained by equating the derivative in (15) to 0 , then yielding an optimal quantile of the predictive cumulative distribution function $F$ for wind power generation at that lead time

$$
Q=F^{-1}\left[\frac{\lambda^{*,+} \alpha^{c}+\lambda^{c a p}\left(1-\alpha^{c}\right)}{\left(\lambda^{*,-}+\lambda^{*,+}\right) \alpha^{c}+\left(\lambda^{b p t,-}+\lambda^{c a p}\right)\left(1-\alpha^{c}\right)}\right]
$$

Similarly, the derivative of (13) with respect to $\alpha^{\mathrm{c}}$ writes

$$
\begin{aligned}
& \frac{\partial O}{\partial \alpha^{c}}\left(Q, \alpha^{c}\right)=\int_{0}^{Q}\left[\begin{array}{c}
\lambda^{*,-}(Q-x)- \\
\lambda^{b p t,-}(Q-x)-\lambda^{s p} x+\lambda^{c a p} x
\end{array}\right] f(x) d x \\
& +\int_{Q}^{1}\left[\lambda^{*,+}(x-Q)-\lambda^{b p t,+}(x-Q)-\lambda^{s p} x+\lambda^{c a p} x\right] f(x) d x
\end{aligned}
$$

Equation (17) is a nonlinear equation in $Q$. Its solutions determine the possible $Q$ values that may be used. Note that Eq. (13) is affine in $\alpha^{c}$, with the sign of the coefficient of $\alpha^{c}$

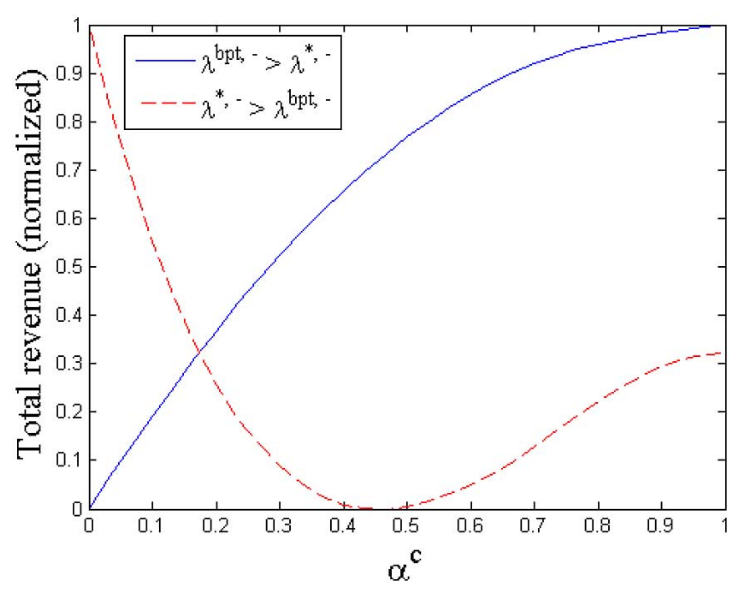

Fig. 4. Illustrative behaviour of Eq. (13) under different relations for energy and reserve penalties. Note, that revenues are maximized for $\alpha^{\mathrm{c}}=0$ or 1, i.e. the wind power producer participates fully in one market or the other.

depending on $\tilde{Q}$. This means that Eq. (13) will be maximized for one of $\alpha^{c}=0$ or $\alpha^{c}=1$. Bids from this proportional strategy will take place in either the energy or the reserve market, but never in both (see Fig. 4). In this way, the energy bid is equal to the total expected energy when the reserve penalty is higher than the energy penalty $\left(\lambda^{\mathrm{bpt},--}>\lambda^{*,--}\right)$, so total availability is submitted to the energy market. On the contrary, when the energy penalty is higher than the reserve penalty $\left(\lambda^{*,--}>\lambda^{b p t,--}\right)$, the total expected power is submitted to the primary reserve market.

\section{B. Constant Strategy Optimization Problem}

The constant strategy assumes that a certain amount of the available power is fixed to participate in the primary reserve market, while the remaining available power is submitted in the energy market [26]. The strategy splits into three distinct domains according to the relationship between the prices on day-ahead markets, and the penalties for energy and reserve deviations.

1) Normal Operation: Under current electricity markets regulatory framework it is more advantageous for wind power plants to provide energy than to provide reserve, since the energy price is usually higher than the reserve price [37]. If renewable energy producers are able to provide in reserve markets, market operators should ensure appropriate price signals to provide incentive for wind power plants to offer their flexibility [4]. I.e. the reserve price must be higher than the energy price $\left(\lambda^{c a p} \geq \lambda^{s p}\right)$. The normal operational hierarchy of electric power systems implies that not meeting a call for reserve is worse than not producing the energy promised, such that the reserve penalty should be higher than the energy regulation penalty $\left(\lambda^{b p t,--} \geq \lambda^{*,--}\right)$. The derivation below assumes that these relations hold. The derivation is also valid for the inverse case $\lambda^{*,--} \geq \lambda^{b p t,--}$ and $\lambda^{s p} \geq \lambda^{c a p}$, but for the above reasons, we expect that the inverse case is unlikely to occur in practice.

Again assuming the wind power plant is a price-taker, the expected available power $Q$, and the primary reserve offer 


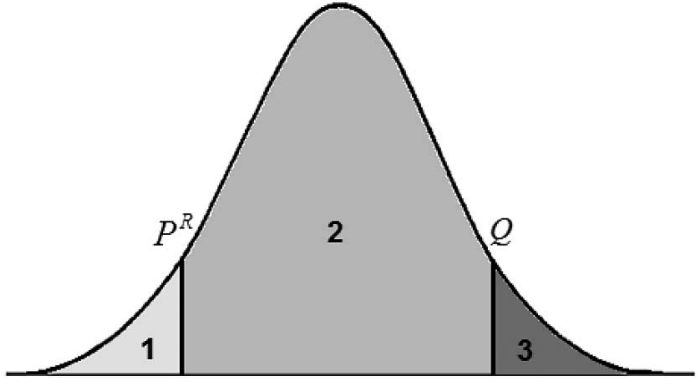

Fig. 5. Regions of operation of constant strategy.

$P^{R}$, are determined from a minimization of the expectation of regulation and penalties costs. This writes

$$
\left(\tilde{Q}, \tilde{P}^{R}\right)=\underset{Q, P^{R}}{\arg \min }\left\{T^{*}+W^{*}-\lambda^{s p} E^{*}-\lambda^{c a p} P^{*}\right\}
$$

This problem contains three different regions of operation (Fig. 5): (i) observed wind energy lower than fixed reserve offer $P^{R} \geq E^{o b s}$, (ii) observed wind power between fixed reserve offer and expected wind power $Q \geq E^{o b s} \geq P^{R}$, and (iii) observed power higher than expected wind power $\mathrm{E}^{\text {obs }} \geq$ $E^{e x p}$.

The mathematical formulation which minimizes the total expected costs $(O)$ is as follows

$$
\begin{aligned}
& O\left(Q, P^{r}\right)=\int_{0}^{P^{r}}\left[\begin{array}{c}
\lambda^{*,-}\left(Q-P^{r}\right)+ \\
\lambda^{b p t,-}\left(P^{r}-x\right)-\lambda^{c a p} x
\end{array}\right] f(x) d x \\
& +\int_{P^{r}}^{Q}\left[\lambda^{*,-}(Q-x)-\lambda^{s p}\left(x-P^{r}\right)-\lambda^{c a p} P^{r}\right] f(x) d x \\
& +\int_{Q}^{1}\left[\lambda^{*,+}(x-Q)-\lambda^{s p}\left(x-P^{r}\right)-\lambda^{c a p} P^{r}\right] f(x) d x
\end{aligned}
$$

The integrals correspond respectively to the operation regions 1, 2, and 3 in Fig. 5. We proceed to minimize this function by differentiation. The derivative of (19) with respect to $Q$ is given by

$$
\begin{aligned}
& \frac{\partial O}{\partial Q}\left(Q, P^{r}\right)=\int_{0}^{P^{r}} \lambda^{*,-} f(x) d x+\int_{P^{R}}^{Q} \lambda^{*,-} f(x) d x \\
& -\left[\lambda^{s p}\left(Q-P^{r}\right)+\lambda^{c a p} P^{r}\right] f(Q)+\int_{Q}^{1}-\lambda^{*,+} f(x) d x \\
& +\left[\lambda^{s p}\left(Q-P^{r}\right)+\lambda^{c a p} P^{r}\right] f(Q)
\end{aligned}
$$

which leads to

$$
Q=F^{-1}\left[\frac{\lambda^{*,+}}{\lambda^{*,-}+\lambda^{*,+}}\right]
$$

The derivative of (18) with respect to $P^{r}$ is

$$
\begin{aligned}
& \frac{\partial O}{\partial P^{r}}\left(Q, P^{r}\right)=\int_{0}^{P^{r}}\left[\lambda^{b p t,-}-\lambda^{*,-}\right] f(x) d x \\
& +\left[\lambda^{*,-}\left(Q-P^{r}\right)-\lambda^{c a p} P^{r}\right] f\left(P^{r}\right)+\int_{P^{r}}^{Q}\left[\lambda^{s p}-\lambda^{c a p}\right] f(x) d x \\
& -\left[\lambda^{*,-}\left(Q-P^{r}\right)-\lambda^{c a p} P^{r}\right] f\left(P^{r}\right)+\int_{Q}^{1}\left[\lambda^{s p}-\lambda^{c a p}\right] f(x) d x
\end{aligned}
$$

This finally yields the optimal bid for reserve participation

$$
P^{r}=F^{-1}\left[\frac{\lambda^{c a p}-\lambda^{s p}}{\lambda^{b p t,-}-\lambda^{*,-}+\lambda^{c a p}-\lambda^{s p}}\right]
$$

2) Special Operation-Reserve Only Market:: There are a few cases where the strategy should be decoupled to participate in a single reserve market: when the energy bid is negative only reserve market participation; and when $\lambda^{b p t,--}<\lambda^{*,--}$ and $\lambda^{c a p} \geq \lambda^{s p}$, the full availability of the wind producer should be submitted to the reserve market.

In that case, the objective function is a special case of that in Eq. (19), i.e.,

$$
\begin{aligned}
O\left(P^{r}\right)= & \int_{0}^{P^{r}}\left[\lambda^{b p t,-}\left(P^{r}-x\right)-\lambda^{c a p} x\right] f(x) d x \\
& +\int_{P^{r}}^{1}\left[\begin{array}{c}
\lambda^{*,+}\left(x-P^{r}\right)- \\
\lambda^{s p}\left(x-P^{r}\right)-\lambda^{c a p} P^{r}
\end{array}\right] f(x) d x
\end{aligned}
$$

The derivative with respect to $P^{R}$ is obtained as

$$
\begin{aligned}
& \frac{\partial O}{\partial P^{r}}\left(P^{r}\right)=\int_{0}^{P^{r}} \lambda^{b p t,-} f(x) d x-\left[\lambda^{c a p} P^{r}\right] f\left(P^{r}\right) \\
& +\int_{P^{r}}^{1}\left[\lambda^{s p}-\lambda^{*,+}-\lambda^{c a p}\right] f(x) d x+\left[\lambda^{c a p} P^{r}\right] f\left(P^{r}\right)
\end{aligned}
$$

resulting in the optimal quantile bid for reserve participation,

$$
P^{r}=F^{-1}\left(\frac{\lambda^{*,+}+\lambda^{c a p}-\lambda^{s p}}{\lambda^{b p t,-}+\lambda^{*,+}+\lambda^{c a p}-\lambda^{s p}}\right)
$$

3) Special Operation-Energy Only Market: In cases where $\lambda^{b p t,--} \geq \lambda^{*,--}$ and $\lambda^{c a p}<\lambda^{s p}$, it is intuitive that the wind power producer will opt to participate in the energy market only. The objective function for this case is a particular case of Eq. (19), given by

$$
\begin{aligned}
O(Q)= & \int_{0}^{Q}\left[\lambda^{*,-}(Q-x)-\lambda^{s p} x\right] f(x) d x \\
& +\int_{Q}^{1}\left[\lambda^{*,+}(x-Q)-\lambda^{s p} x\right] f(x) d x
\end{aligned}
$$

The derivative of (27) with respect to $E^{\exp }$ becomes

$$
\frac{\partial O}{\partial Q}(Q)=\int_{0}^{Q} \lambda^{*,-} f(x) d x+\int_{Q}^{1} \lambda^{*,+} f(x) d x
$$

which results in the well-known quantile for energy-only participation

$$
Q=F^{-1}\left(\frac{\lambda^{*,+}}{\lambda^{*,-}+\lambda^{*,+}}\right)
$$

\section{Strategies Summary}

A general overview of the analytical formulas to obtain optimal offers in both markets and for both strategies is given in Table I. 
TABLE I

SUMMARY OF OPTIMAL BIDS

\begin{tabular}{lcc|cc}
\hline \hline \multirow{2}{*}{ Strategy } & \multicolumn{2}{c|}{ Normal operation } & \multicolumn{2}{c}{ Special operation } \\
& $Q$ & $P^{r}$ & $Q$ & $P^{r}$ \\
\hline Constant & $(21)$ & $(23)$ & $(29)$ & $(26)$ \\
Proportional & $(16)$ & $(17)$ & - & - \\
\hline \hline
\end{tabular}

TABLE II

Prices and Penalties in Energy and Reserve Market

\begin{tabular}{cc|cc}
\hline \hline Energy & Price $(€ / \mathrm{MWh})$ & Reserve & Price $(€ / \mathrm{MW})$ \\
\hline$\lambda^{s p}$ & 22 & $\lambda^{\text {cap }}$ & 25 \\
$\lambda^{c,+}$ & 17 & $\lambda^{b p t,+}$ & 0 \\
$\lambda^{c,-}$ & 32 & $\lambda^{p t,-}$ & 60 \\
\hline \hline
\end{tabular}

TABLE III

Simulation Results For STRATEgies BASEd ON PROPORTIONAL, CONSTANT, AND ENERGY-ONLY MARKET STRATEGY

\begin{tabular}{lccc}
\hline \hline Strategy & Proportional & Constant & Energy-only \\
\hline Energy bid (MWh) & 7.018 & 3.516 & 7.018 \\
Reserve bid (MW) & 0 & 3.502 & - \\
Total expected power $(\mathrm{MW})$ & 7.018 & 7.018 & 7.018 \\
\hline Expected inflow $(\Theta)$ & 225.48 & 235.61 & 225.48 \\
Expected costs $(€)$ & 29.92 & 33.03 & 29.92 \\
Expected revenue $(€)$ & 195.56 & 202.58 & 195.56 \\
\hline \hline
\end{tabular}

TABLE IV

SimUlation RESUlts FOR $\lambda^{c a p}$ LARGER Than $\lambda^{s p}$ FOR Proportional, Constant, and Energy-OnLy Market Strategies

\begin{tabular}{lccc}
\hline \hline Strategy & Proportional & Constant & Energy-only \\
\hline Energy bid $(\mathrm{MWh})$ & 0 & 0 & 7.018 \\
Reserve bid $(\mathrm{MW})$ & 12.063 & 9.936 & - \\
Total expected power $(\mathrm{MW})$ & 12.063 & 9.936 & 7.018 \\
\hline Expected inflow $(€)$ & 381.57 & 365.24 & 225.48 \\
Expected costs $(€)$ & 75.72 & 55.86 & 29.92 \\
Expected revenue $(€)$ & 305.85 & 309.40 & 195.56 \\
\hline \hline
\end{tabular}

\section{EVAluation of OfFERING Strategy}

\section{A. Test Cases}

1) Base Case:: The base case is based on the following parameters and assumptions. The wind power plant has a $30 \mathrm{MW}$ installed capacity. An example probabilistic wind power forecasts takes the form of a beta distribution with shape parameters $\alpha=2$ and $\beta=4$. The expected revenue is evaluated using 1000 samples for wind production drawn from this distribution. Besides, Table II gathers the prices for energy and reserve in our numerical example, as well as the unit penalty for up and down deviations from contract.

The evaluation of the proportional strategy is performed by an iterative process. $\alpha^{c}$ is assumed to vary between 0 and 1 with steps of 0.03. $Q$ is determined based on Eq. (16) for each $\alpha^{c}$. The total revenue for each given $\alpha^{c}$ is determined.

The constant strategy is first analyzed based on the most realistic assumption on the relation between penalties and market prices, i.e., such that $\lambda^{b p t,--} \geq \lambda^{*,--}$ and $\lambda^{c a p} \geq \lambda^{s p}$. In this case, Eqs. (21) and (23) are used to determine the energy and the reserve bid, respectively.

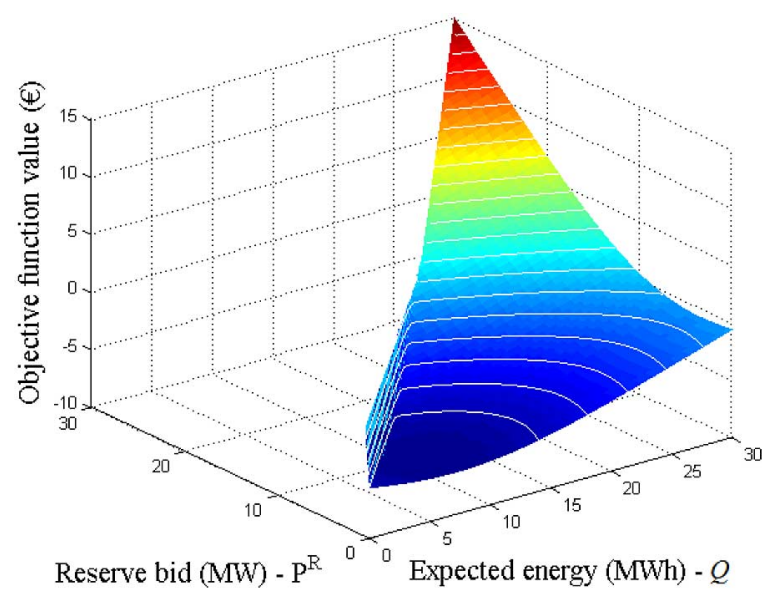

Fig. 6. Objective function behavior for constant strategy, based on base case data.

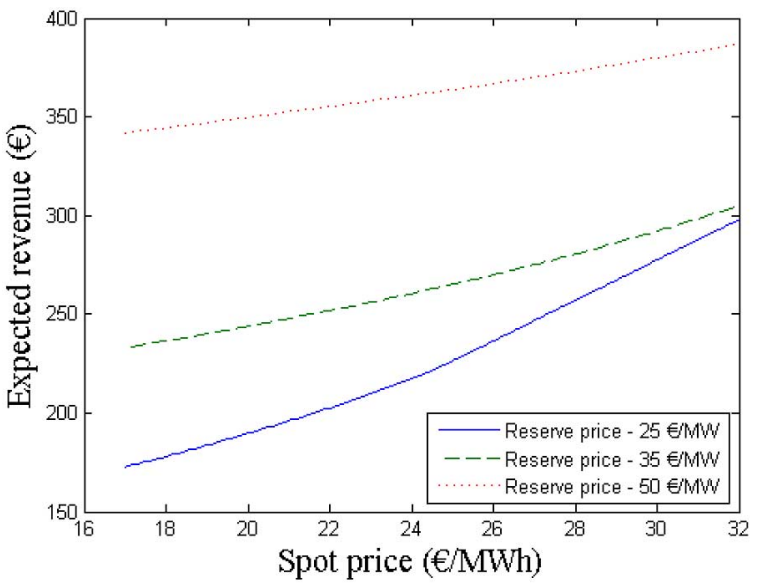

Fig. 7. Expected revenue for constant strategy under variation of day-ahead energy and primary reserve market prices.

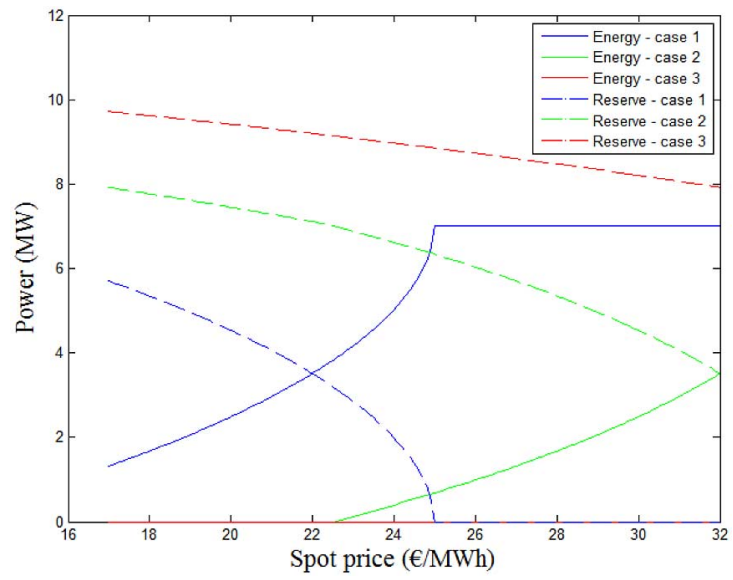

Fig. 8. Expected share of energy and reserve for constant strategy under variation of day-ahead energy and primary reserve market prices. Dashed lines represents the primary reserve share for each case of primary reserve price (case 1 - reserve price of $25 € / \mathrm{MW}$; case 2 - reserve price of $35 € / \mathrm{MW}$; and case 3 - reserve price of $50 € / \mathrm{MW}$ ).

Table III shows a comparison between three different strategies for participation in electricity markets (proportional, constant and energy-only). The expected revenue is the difference 
TABLE V

Cumulative Simulation Results of Two Years Data for Proportional, Constant, and Energy-Only Market Strategies

\begin{tabular}{lcc|cc|cc}
\hline \hline Strategy & \multicolumn{2}{c|}{ Proportional } & \multicolumn{2}{c|}{ Constant } & \multicolumn{2}{c}{ Energy-only } \\
Data & Forecast & Deployed & Forecast & Deployed & Forecast & Deployed \\
\hline Energy bid $(\mathrm{MWh})$ & 0 & 0 & 11930.297 & 18334.760 & 20490.612 & 23519.591 \\
Reserve bid (MW) & 26195.071 & 23519.591 & 8686.597 & 5184.831 & 0 & 0 \\
Total expected power $(\mathrm{MW})$ & 26195.071 & 23519.591 & 20616.894 & 23519.591 & 20490.612 & 23519.591 \\
\hline Expected inflow $(\Theta)$ & 684350.67 & 607650.89 & 604799.61 & 567634.54 & 576688.69 & 552409.90 \\
Expected costs $(\Theta)$ & 0 & 87673.49 & 0 & 90109.12 & 0 & 89339.00 \\
Expected revenue $(\Theta)$ & 684350.67 & 519977.40 & 604799.61 & 477525.42 & 576688.69 & 463070.90 \\
\hline \hline
\end{tabular}
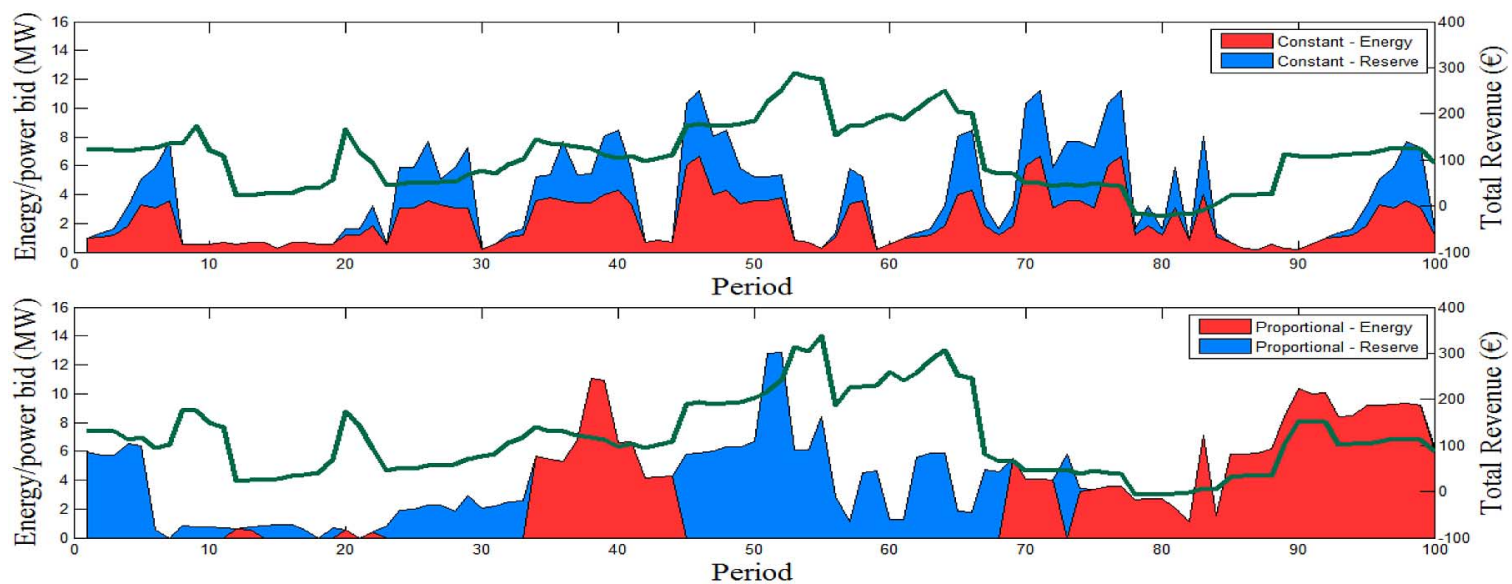

Fig. 9. Constant and proportional strategies behavior over the time, under real data adapted from [13].

between the expected inflow and expected costs (defined in Sect. IV). The energy-only strategy is based on the common newsvendor problem [13]. Thus, the quantile for this strategy is given by Eq. (29). Observing the behavior of the strategies in Table III, one can verify that constant strategy has higher expected return than the other strategies.

2) Full Reserve Case: Assuming that $\lambda^{\text {cap }}$ is much larger than $\lambda^{s p}$, for instance $\lambda^{c a p}=40 € / M W$, the strategies may split the energy and reserve bids differently. Table IV compare the strategies participation in both energy and primary reserve market for this capacity price.

One can verify that there is a change in the behavior of both proposed strategies. Both strategies allocate all the available energy to the primary reserve market. This is since the revenue from the primary reserve market is much higher than the revenue from the energy market. Both proposed strategies get better results than the energy-only strategy.

\section{B. Constant Strategy Behavior}

1) Objective Function Behavior: The objective function for the base case is depicted in Fig. 6. One can verify that this function is convex, allowing to obtain a unique optimal solution. The expected reserve bid can never be higher than the total expected energy, hence the triangular cutoff for higher expected reserve.

2) Constant Strategy Performance Under Different Spot and Primary Reserve Market Prices: The behavior of the constant strategy strongly depends on the difference between day-ahead energy and primary reserve market prices. Fig. 7 depicts the behavior of the strategy under different spot and reserve market prices. The simulation is performed under the base case data with variation in spot and primary reserve prices.

The spot prices varies between 17 and $32 € / M W h$, while the primary reserve market price is represented by three cases, 25 , 35 and $50 € / \mathrm{MW}$, respectively.

The simulation shows that increasing primary reserve price leads to higher revenue, as expected. As long as the spot price increases, the expected revenue increases too, since the strategy splits its available power for energy and reserve. Thus, as long as one of the day-ahead energy spot or capacity price improves, the revenue tends to increase.

Fig. 8 illustrates the dependency of the share of the offers into the energy and reserve markets as a function of day-ahead energy and reserve capacity prices. The reserve share tends to reduce with the increase of the spot price, as expected. However, at a certain point, the reserve market no longer generates higher profit than the energy market, making that full availability is submitted to the energy market. This occurs when the spot price is higher than $25 € / M W h$. In case 1 (reserve price of $25 € / \mathrm{MW}$ ) this occurs because the primary reserve penalty is higher than the energy penalty, so there is no incentive to participate in the primary reserve market. The intersection between energy and reserve curve for case 1, gives precisely the result of the base case for the constant strategy.

\section{Strategies Behavior Over Time-Real Data}

The data and assumptions used for simulation of both strategies over time are the same used in [13]. We consider a wind farm of $15 \mathrm{MW}$ participating in the Nord Pool, where the wind 
farm data is based on power measurements and a series of $48 \mathrm{~h}$ ahead point predictions between March 2001 and April 2003 [13]. Nord Pool prices and penalties between 2001 and 2003 are used. Reserve penalty is assumed to be $50 \%$ higher than the capacity price in the primary reserve market.

The cumulative data results for energy and revenue over the two years for each strategy are shown in Table V. In overall, one can see that the proportional strategy submits more power to the energy and reserve markets than the constant strategy. In the same perspective, the proportional strategy gets more expected revenue than constant strategy. Furthermore, proportional and constant strategies improve the revenue of wind power producers relative to the energy-only strategy by about $12 \%$ and $3 \%$, respectively. In addition, Table $\mathrm{V}$ provides a comparison for each strategy between the expected results under forecast scenarios and under deployed wind power.

Fig. 9 illustrates the different behavior of both proportional and constant strategies over time. It can be seen that in most of the periods, the constant strategy splits the available power for participation in both markets. On contrary, the proportional strategy tends to submit all the available power to one market only. From the economic point of view, both strategies are balanced. I.e., in some periods, the constant strategy may get more revenue than the proportional one, however, the opposite also occur. This is because of the different assumptions on the formulation of each strategy, yielding different behavior in the market.

\section{CONCLUSION}

The increasing flexibility of wind power plants will allow them to provide more market services, such as primary reserve, in the future.

This work formulates and derives optimal offering strategies for wind power plants participation in energy and primary reserve markets. Two strategies (proportional and constant reserve offering strategies) were considered. Both strategies have different behavior and flexibility, however, they increase wind power owners expected profits as compared to an energyonly bid. The results show that such strategies provide additional profits in expectation. The proportional strategy leads to a binary behavior where all the available energy is submitted in either the energy or the reserve market. In contrast, the constant strategy enables a joint participation of wind power plants in both energy and primary reserve markets. In addition, results show that these offering strategies strongly depend on the market prices and penalties for energy and primary reserve. An important conclusion from this work is that, even though turbines may have the technical ability to provide reserves, they may not always do so in the current market framework, since the relative profitability and penalties in both energy and reserve markets will drive the behavior of wind power producers.

Future work will focus on improvements of the strategies considering that the share for energy and reserve submitted in the day-ahead market can change in the balancing market.

\section{ACKNOWLEDGMENT}

The authors would like to thank three reviewers whose comments allowed to improve the contents and presentation of this work.

\section{REFERENCES}

[1] Energinet.dk. (2014). “Annual report 2013,” pp. 1-139, 2014, [Online]. Available: https://www.energinet.dk/SiteCollectionDocuments/Engelske \%20dokumenter/Om\%20os/Annual\%20Report\%202013.pdf

[2] Danish Government, "Energy strategy 2050-From coal, oil and gas to green energy," Danish Energy Agency, pp. 1-66, 2011 [Online]. http://www.ens.dk/sites/ens.dk/files/dokumenter/publikationer/ downloads/energy_strategy_2050.pdf

[3] M. A. Ortega-Vazquez and D. S. Kirschen, "Estimating the spinning reserve requirements in systems with significant wind power generation penetration," IEEE Trans. Power Syst., vol. 24, no. 1, pp. 114-124, Feb. 2009.

[4] E. Ela, B. Kirby, N. Navid, and J. C. Smith, "Effective ancillary services market designs on high wind power penetration systems," in Proc. IEEE Power Energy Soc. Gen. Meeting, 2012, pp. 1-8.

[5] H. Lund et al., "System and market integration of wind power in Denmark," Energy Strategy Rev., vol. 1, pp. 143-156, 2013.

[6] Y. Dvorkin, M. A. Ortega-Vazquez, and D. S. Kirschen, "Wind generation as a reserve provider," IET Gener. Transm. Distrib., vol. 9, no. 8, pp. 779787,2015

[7] D. Nock, V. Krishnan, and J. D. McCalley, "Dispatching intermittent wind resources for ancillary services via wind control and its impact on power system economics," Renew. Energy, vol. 71, pp. 396-400, 2014.

[8] G. Michalke and A. D. Hansen, "Grid support capabilities of wind," in Handbook. of Wind Power Systems. New York, NY, USA: Springer, pp. 569-590, 2014.

[9] L. Zeni, A. J. Rudolph, J. Münster-Swendsen, I. Margaris, A. D. Hansen, and P. Sørensen, "Virtual inertia for variable speed wind turbines," Wind Energy, vol. 16, pp. 1225-1239, 2013.

[10] R. Doherty and M. O'Malley, "A new approach to quantify reserve demand in systems with significant installed wind capacity," IEEE Trans. Power Syst., vol. 20, no. 2, pp. 587-595, May 2005.

[11] B. Kirby, M. Milligan, and E. Ela, "Providing minute-to-minute regulation from wind plants," in Proc. 9th Annu. Int. Workshop Large-Scale Integr. Wind Power Power Syst. Transm. Netw. Offshore Wind Power Plant, Quebec, Canada, pp. 1-11, Oct., 2010.

[12] J. Liang, S. Grijalva, and R. G. Harley, "Increased wind revenue and system security by trading wind power in energy and regulation reserve markets," IEEE Trans. Sustain. Energy, vol. 2, no. 3, pp. 340-347, Jul. 2011.

[13] P. Pinson, C. Chevallier, and G. N. Kariniotakis, "Trading wind generation from short-term probabilistic forecasts of wind power," IEEE Trans. Power Syst., vol. 22, no. 3, pp. 1148-1156, Aug. 2007.

[14] J. Usaola and M. Á. Moreno, "Optimal bidding of wind energy in intraday markets," in Proc. 6th Int. Conf. Eur. Energy Market (EEM'09), 2009, pp. 1-7.

[15] J. M. Morales, S. Member, A. J. Conejo, and J. Pérez-ruiz, "Short-term trading for a wind power producer," IEEE Trans. Power Syst., vol. 25, no. 1, pp. 554-564, Feb. 2010.

[16] A. Botterud et al., "Wind power trading under uncertainty in LMP markets," IEEE Trans. Power Syst., vol. 27, no. 2, pp. 894-903, May 2012.

[17] E. Y. Bitar, R. Rajagopal, P. P. Khargonekar, K. Poolla, and P. Varaiya, "Bringing wind energy to market," IEEE Trans. Power Syst., vol. 27, no. 3, pp. 1225-1235, Aug. 2012.

[18] M. Zugno, T. Jónsson, and P. Pinson, "Trading wind energy on the basis of probabilistic forecasts both of wind generation and of market quantities," Wind Energy, vol. 16, no. 6, pp. 909-926, 2013.

[19] M. Vilim and A. Botterud, "Wind power bidding in electricity markets with high wind penetration," Appl. Energy, vol. 118, pp. 141-155, 2014.

[20] C. J. Dent, J. W. Bialek, and B. F. Hobbs, "Opportunity cost bidding by wind generators in forward markets: Analytical results," IEEE Trans. Power Syst., vol. 26, no. 3, pp. 1600-1608, Aug. 2011.

[21] J. Matevosyan and L. Söder, "Minimization of imbalance cost trading wind power on the short-term power market," IEEE Trans. Power Syst., vol. 21, no. 3, pp. 1396-1404, Aug. 2006. 
[22] M. Zugno, J. M. Morales, P. Pinson, H. Madsen, and A. Sets, "Pool strategy of a price-maker wind power producer," IEEE Trans. Power Syst., vol. 28, no. 3, pp. 3440-3450, Aug. 2013.

[23] L. Baringo and A. J. Conejo, "Strategic offering for a wind power producer," IEEE Trans. Power Syst., vol. 28, no. 4, pp. 4645-4654, Nov. 2013.

[24] S. J. Kazempour and H. Zareipour, "Equilibria in an oligopolistic market with wind power production," IEEE Trans. Power Syst., vol. 29, no. 2, pp. 686-697, Mar. 2014.

[25] K. C. Sharma, R. Bhakar, and H. P. Tiwari, "Strategic bidding for wind power producers in electricity markets," Energy Convers. Manage., vol. 86, pp. 259-267, 2014.

[26] L. Baringo and A. J. Conejo, "Offering strategy of wind-power producer: A multi-stage risk-constrained approach," IEEE Trans. Power Syst., 2015, pp. 1-10, doi: 10.1109/TPWRS.2015.2411332.

[27] T. Dai, S. Member, W. Qiao, and S. Member, "Optimal bidding strategy of a strategic wind power producer in the short-term market," IEEE Trans. Sustain. Energy, vol. 6, no. 3, pp. 707-719, Jul. 2015.

[28] M. Shafie-khah, A. A. S. de la Nieta, J. P. S. Catalão, and E. HeydarianForushani, "Optimal self-scheduling of a wind power producer in energy and ancillary services markets using a multi-stage stochastic programming," in Proc. Smart Grid Conf. (SGC), 2014, pp. 1-5.

[29] Y. Wang, "Evaluation de la performance des réglages de fréquence des eoliennes à l'echelle du système electrique: Application à un cas insulaire," (in French), Ph.D. dissertation, L2EP, Ecole Centrale de Lille, Villeneuve-d'Ascq, France, 2012.

[30] Y. Wang, H. Bayem, M. Giralt-Devant, V. Silva, X. Guillaud, and B. Francois, "Methods for assessing available wind primary power reserve," IEEE Trans. Sustain. Energy, vol. 6, no. 1, pp. 272-280, Jan. 2015.

[31] S. Krohn, P. E. Morthorst, and S. Awerbuch, "The economics of wind energy," EWEA-Eur. Wind Energy Assoc., pp. 1-156, 2009 [Online]. Available: http://www.ewea.org/fileadmin/files/library/ publications/reports/Economics_of_Wind_Energy.pdf

[32] Energinet.dk, "Wind power to combat climate change-How to integrate wind energy into the power system," pp. 1-56, 2009 [Online]. Available: http://energinet.dk/SiteCollectionDocuments/Engelske\%20dokumenter/ Klimaogmiljo/Wind\%20power\%20magazine.pdf

[33] K. Skytte, "The regulating power market on the Nordic power exchange nord pool: An econometric analysis," Energy Econ., vol. 21, no. 4, pp. 295-308, 1999.

[34] Energinet.dk, "Regulation C2: The balancing market and balance settlement," Doc. no, 251673-06, pp. 1-20, 2008 [Online]. Available: https://www.energinet.dk/SiteCollectionDocuments/Engelske\%20 dokumenter/El/Regulation\%20C2\%20The\%20balancing\%20market\%20 and $\% 20$ balance $\% 20$ settlement.pdf

[35] A. J. Conejo, M. Carrión, and J. M. Morales, Decision Making Under Uncertainty in Electricity Markets. New York, NY, USA: Springer, 2010.

[36] H. Raiffa and R. Schlaifer, Applied Statistical Decision Theory. Boston, MA, USA: Division of Research, Harvard Business School, 1961.

[37] B. Kirby and A. Tuohy, "Profitability of wind plants providing ancillary services-Regulation and spinning reserve," 2013 [Online]. Available: http://www.nrel.gov/electricity/transmission/pdfs/wind_workshop2_ 24kirby.pdf

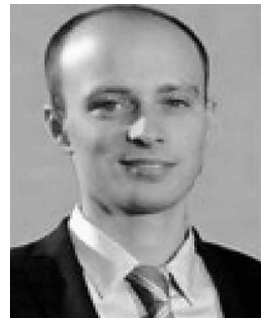

Tiago Soares received the B.Sc. and M.Sc. degrees in electrical engineering from the School of Engineering, Polytechnic Institute of Porto, Porto, Portugal, in 2010 and 2013, respectively. He is currently pursuing the Ph.D. degree at the Technical University of Denmark, Kgs. Lyngby, Denmark. His research interests include electricity markets, distributed generation, energy resources management and optimization, optimization under uncertainty, and future power systems.

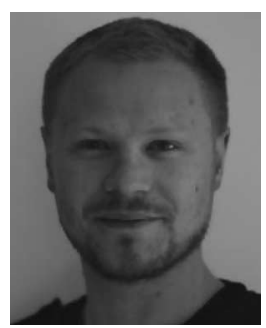

Pierre Pinson (M'11-SM'13) received the M.Sc. degree in applied mathematics from the National Institute for Applied Sciences (INSA), Toulouse, France, and the Ph.D. degree in energetics from Ecole des Mines de Paris, Paris, France. He is a Professor with the Department of Electrical Engineering, Centre for Electric Power and Energy, Technical University of Denmark, Kgs. Lyngby, Denmark, also heading a group focusing on Energy Analytics and Markets. His research interests include forecasting, uncertainty estimation, optimization under uncertainty, decision sciences, and renewable energies. He is an Editor for the IEEE TRANSACTIONS ON POWER SySTEMS and the International Journal of Forecasting and for Wind Energy.

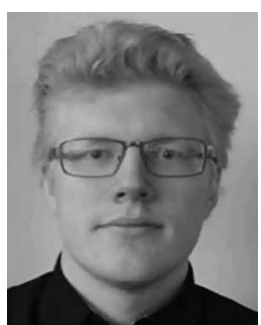

Tue V. Jensen received the M.Sc. degree in physics from Aarhus University, Aarhus, Denmark, in 2013. $\mathrm{He}$ is currently pursuing the Ph.D. degree at the Technical University of Denmark, Kgs. Lyngby, Denmark. His research interests include renewable energy markets, complex networks, and gaming aspects of energy markets.

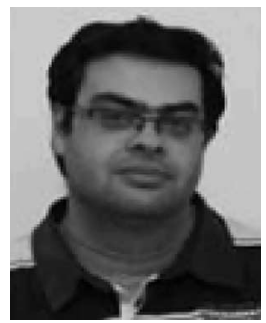

Hugo Morais (S'08-M'11) received the Ph.D. degree in electrical engineering from the University of Trás-os-Montes e Alto Douro, Vila Real, Portugal. $\mathrm{He}$ is a Researcher with the Mesures et système d'Information des Réseaux Electriques Group, Électricité de France, Clamart, France. His research interests include distributed energy resources management, virtual power players, smart grids, future power systems, agents technology, and power systems visualization. 